\title{
Introdução aos estudos curriculares
}

\section{Introduction to curriculum studies}

\author{
Adelcio Machado dos Santos ${ }^{1 *}$, Rita Marcia Twardowski ${ }^{1}$, Audete Alves dos Santos Caetano ${ }^{1}$, \\ Danielle Martins Leffer ${ }^{1}$, Alisson André Escher ${ }^{1}$
}

\begin{abstract}
RESUMO
A temática curricular esteve presente ao longo do século XX nos debates referentes a questões educacionais. Como resultado desses debates, o currículo deixou de ser entendido como sendo a simples relação e distribuição das disciplinas ou a declaração de áreas e temas. O currículo não se constitui simplesmente como uma seriação de estudos, denominados de base curricular de um curso, ou uma listagem de conhecimentos e conteúdos das mais diversas disciplinas para serem ensinados de modo sistemático. $\mathrm{O}$ currículo, como resultado de uma construção política, deve compreender a soma de todo tipo de ações e aprendizagens, bem como de ausências que os educandos obtêm como consequiência de estarem sendo escolarizados. A política curricular compreende a racionalização do processo de desenvolvimento do currículo com a regulação do conhecimento que constitui a face visível da realidade escolar, sendo que está relacionada com toda decisão ou o condicionamento dos conteúdos e da prática de desenvolvimento do currículo, partindo-se dos contextos de decisão política e administrativa.
\end{abstract}

Palavras-chave: Currículo; Cultura; Educação; Políticas educacionais.

\begin{abstract}
The curriculum theme has been present throughout the twentieth century in debates concerning educational issues. As a result of these debates, the curriculum is no longer understood as a simple list and distribution of subjects or a statement of areas and themes. The curriculum is not simply a series of studies, called the curricular base of a course, or a list of knowledge and content of various subjects to be taught in a systematic way. The curriculum, as a result of a political construction, should comprise the sum of all kinds of actions and learning, as well as absences that students obtain as a consequence of being schooled. The curriculum policy includes the rationalization of the curriculum development process with the regulation of knowledge that is the visible face of school reality, and is related to any decision or conditioning of the content and practice of curriculum development, starting from the contexts of political and administrative decisions.
\end{abstract}

Keywords: Curriculum; Culture; Education; Educational policies.

\footnotetext{
${ }^{1}$ Universidade Alto Vale do Rio do Peixe - UNIARP

* E-mail: adelciomachado@gmail.com
} 


\section{INTRODUÇÃO}

A temática curricular esteve sempre presente ao longo do século XX nos debates referentes a questões educacionais. Da referida centúria, emergiram produções referentes à racionalização no processo de construção, desenvolvimento e teste de currículos. No final dos anos 40, emerge a idéia de organização e desenvolvimento curricular. Na década de 70, o questionamento provocado pelas teorizações pedagógicas críticas. (OLIVEIRA; SÜSSEKIND, 2017; POPKEWITZ, 2020).

No Brasil, de acordo com Oliveira e Süssekind (2017), a questão também esteve presente, a partir das propostas curriculares centralizadas para o ensino secundário. Contudo, somente a partir dos anos 70, passou-se a trabalhar cada vez mais com a idéia de núcleo comum, para a Educação Básica, e de currículos mínimos, para a Educação Superior. E na segunda metade da década de 90, surgiram na República as propostas de Diretrizes, Referenciais e Parâmetros Curriculares para a educação básica e maior autonomia em relação às matrizes curriculares da educação superior.

Conquanto, se desconheça a época em que a acepção pedagógica do vocábulo currículo começou a ser utilizada, é certo que isso já acontecia, posto que sobremodo limitadamente, nos primeiros anos do século XX. Naquela época, o termo curriculum era tomado no sentido do conjunto das matérias ou disciplinas ministradas, mas se distinguindo dos conteúdos específicos de cada uma delas. (SANTOS, 2020).

Destarte, de fato, nos países de língua derivada do latim, denominar de currículo os planos de estudo, os programas ou, de modo geral, os documentos nos quais se define a estrutura e o funcionamento dos cursos, é um hábito que só foi adquirido nas derradeiras dezenas de anos, consonantemente preleciona Santos (2020).

Não podemos esquecer de destacar, mais intensamente nas últimas décadas do século XX, as abordagens pós-modernas de educação.

O resultado dos debates em relação aos currículos escolares abandonou, atualmente, a ideia de ser entendido, simplesmente, como sendo a relação e distribuição das disciplinas com as suas respectivas cargas horárias, ou correspondendo simplesmente ao número de horas-aula e dos dias letivos. 


\section{CURRÍCULO: UMA DEFINIÇÃO}

O currículo, nos termos do magistério de Menegolla e Sant'ana (1998), não se constitui apenas em seriação de estudos que são denominados de base curricular para um determinado curso, ou uma listagem de conhecimentos e conteúdos das mais diversas disciplinas para serem ensinados de modo sistemático na sala de aula. Não deve ser compreendido somente como uma relação de conteúdos ou conhecimentos delimitados e isolados, estabelecendo tópicos estagnados, em relação "fechada", sem uma integração envolvente e ampla com todas as dimensões do conhecimento.

Currículo, conforme Menegolla e Sant'ana (1998), não é simplesmente um plano padronizado, no qual estão relacionados alguns princípios e normas para o funcionamento da escola, como se constituísse um manual de instruções para se poder acionar uma máquina.

Não obstante, o currículo também não se delimita em relacionar matérias, cargas horárias ou outras normas condizentes com a vida escolar que um educando necessita cumprir no contexto escolar. (DUARTE, 2018). Neste sentido, o currículo não é algo restrito ao âmbito da escola ou à sala de aula.

$\mathrm{Na}$ realidade, de acordo com Menegolla (1998), o currículo é algo muito abrangente, dinâmico e existencial. Ele é entendido numa dimensão profunda e real que envolve todas as situações circunstanciais da vida escolar e social do aluno. Pode-se afirmar que é a escola em ação, ou seja, a vida do aluno e de todos os que sobre ele possam ter determinada influência. É o interagir de tudo o que participa e, por conseguinte, interfere no processo educacional da pessoa do aluno.

Em outras palavras, o currículo diz respeito a todas as situações educacionais que o aluno vive, dentro e fora do contexto escolar, sendo que, por isso, a dimensão do currículo não se restringe a questões ou aos problemas que são vivenciados diretamente dentro do âmbito da escola.

No entendimento de Menegolla (1998), o currículo nasce para além das paredes da escola e seu passo inicial é dado fora da escola para poder entrar nela. Esse procedimento é justificável, uma vez que o currículo é constituído por todos os atos da vida de uma pessoa, tanto do passado quanto do presente e, tendo ainda, uma perspectiva de futuro. (DIAS; MENEZES, 2017). 
O currículo também não se restringe ao ambiente escolar, pois o aluno não está enclausurado dentro de uma escola ou de uma sala de aula. Nas palavras de Menegolla (1998) a vida do aluno não corresponde somente aquilo que o educador pretende transmitir dentro da sala de aula. Grande parte das experiências são adquiridas e assimiladas fora da escola, sendo que estes conhecimentos não escolares acabam por integrar o seu "Curriculum Vitae".

Pode-se, também afirmar, conforme Menegolla (1998), que o currículo deve ser a organização da vida que o aluno vive fora e dentro da escola; sendo com isso, a estruturação de toda a ação desencadeada na escola, para organizar e desenvolver o "Curriculum Vitae" do aluno.

Em suma, o currículo não deve se limitar a simples estruturação das matérias de ensino como algo delimitado, sendo que se deve ir bem mais além, aproveitar as experiências, as atividades, toda a ação do educando, da escola e da sociedade, exercidas sobre o educando, com a finalidade de obter os objetivos educacionais. Tudo o que promover e ativar o processo educativo deve constituir o currículo escolar.

Nesta definição abrangente do autor acima referido, todas as atividades realizadas e vivenciadas pelo educando e por todo o pessoal envolvido com o educando, necessariamente, constituem o currículo escolar. Em decorrência disto, pode-se dizer que o currículo é a vida do aluno e da escola em ação, dinâmica e constante. (MORAN, 2017).

Já Bianchi (2001) diferencia duas concepções relacionadas ao termo currículo. A primeira delas se refere à linguagem corrente, situada fora do espaço escolar, no qual o termo currículo diz respeito, na maior parte das vezes, a um apontamento biográfico (curriculum vitae), geralmente elaborado para um fim específico e no qual se atribui ênfase aos aspectos da preparação acadêmica, da carreira profissional e da experiência de vida, considerados mais relevantes para tal objetivo. Uma segunda acepção do termo é utilizada no âmbito específico da educação escolar, sendo que o termo currículo se refere, habitualmente, ao plano de estudos, ou seja, um conjunto de conteúdos a serem ensinados e sua seqüência temporal, apesar de algumas vezes identificar-se com as próprias atividades escolares.

Sob o ponto de vista de Corazza (2001), no domínio de uma "metafórica" do currículo, constituída pelas teorias da linguagem estruturalista e pós-estruturalista, podese pensar que um currículo é uma linguagem. 
Neste sentido, o currículo é dotado de um caráter eminentemente construcionista. (MUYLAERT, 2020). Ao conceber o currículo como uma linguagem, nele se identificam significantes, significados, sons, imagens, conceitos, falas, língua, posições, discursivas, representações, metáforas, metonímias, ironias, invenções, fluxos, cortes, entre outros.

No entendimento de Corazza (2001), ao atribuir-se essa condição "linguajeira" a um currículo, diz-se que a natureza de sua discursividade é arbitrária e ficcional, por ser histórica e socialmente construída

. Que seu discurso fornece apenas uma das tantas maneiras de formular o mundo, de interpretar o mundo, e de atribuir-lhe sentidos. Que sua sintaxe e semântica possui uma função constitutiva daquilo que enuncia como sendo "escola", "aluno/a", "professor/a", "pedagogia" e inclusive "currículo".

Do mesmo modo, as palavras que um currículo utiliza para nomear as coisas, os fatos, a realidade e os sujeitos são produtos de seu sistema de significação que disputa com outros sistemas. Um currículo, como linguagem, é uma prática social, discursiva e não-discursiva, que se corporifica em instituições, saberes, normas, prescrições morais, regulamentos, programas, relações, valores, modos de ser sujeito. (CORAZZA, 2001).

\section{POLÍTICAS CURRICULARES}

No entendimento de Macdonald (apud Pacheco, 2003), o parâmetro principal do currículo não é o aluno, nem a sociedade, nem a herança cultural, porém o processo político de escolaridade.

Desta forma, pretende-se afirmar que o processo político é a rede de estruturas, papéis, normas e relações interpessoais que operam no processo de escolaridade. A consideração do currículo e da educação, como uma construção política, parte do pressuposto de que a escola constitui o veículo dessa atividade política, isto é, uma forma particular de organizar o poder e as influências que se encontraram nas suas práticas cotidianas. (THIESEN, 2019).

Entretanto, reduzir o currículo a uma atividade política é considerá-lo um texto institucionalizado, legitimado por uma função burocrática direcionada para a eficiência e melhoria constante.

Neste sentido, o currículo é um texto de solução do problema da representação que interliga os processo de produção e de reprodução, englobando a seleção de 
conteúdos, a organização de conhecimentos e destrezas, e a orientação de métodos de transmissão.

Por ser a política uma necessidade para a vida humana, tanto no campo individual como social, a política curricular representa a racionalização do processo de desenvolvimento do currículo nomeadamente com a regulação do conhecimento que é a face visível da realidade escolar, juntamente com o papel desempenhado por cada ator educativo, dentro de uma determinada estrutura de decisões relacionadas à construção do projeto formativo.

De acordo com Pacheco (2003), em termos formais, a política curricular diz respeito ao conjunto de leis e regulamentações que se referem ao que deve ser ensinado nas escolas. Assim, a política curricular compreende toda decisão ou o condicionamento dos conteúdos e da prática de desenvolvimento do currículo, partindo-se dos contextos de decisão política e administrativa.

A política curricular ainda planeja parâmetros de atuação com um grau de flexibilidade para os diferentes agentes que moldam o currículo. Na medida em que o regula, a política é o primeiro condicionante direto do currículo e, indiretamente, é por meio da sua ação que outros agentes são moldados.

Nesta perspectiva, a política curricular consiste em uma ação simbólica, representando uma ideologia para a organização da autoridade e que engloba tanto as decisões das instâncias da administração central como as decisões dos contextos escolares.

Segundo Pacheco (2003), esta política é implementada através de três tipos de instrumentos: normativos explícitos e objetivos (leis, decretos, portarias, despachos); normativos interpretativos e subjetivos (circulares e ofícios circulares); documentos de orientação e apoio (textos de apoio, documentos internos da escola). Deste modo, a política é, ao mesmo tempo, processo e produto, abrangendo a produção de intenções, ou de textos, como a realização de práticas ou de ações concretas. (MONTEIRO; AZAMBUJA, 2018).

Uma vez que a política não se reduz a um simples texto e o Estado constitui somente um dos teorizadores, os textos curriculares, advindos da administração central, são documentos de trabalho que simbolizam o discurso oficial do Estado que agrega interesses diferentes e alianças construídas a diversos níveis de ação. 
Entretanto, conforme Pacheco (2003), são textos macropolíticos que estão inseridos numa determinada linha de racionalidade técnica, onde os contextos de microdecisão política são deixados à margem. Desta forma, há que se reconhecer que as decisões políticas curriculares são caracterizadas pela fragmentação e pela multicentralização.

Não obstante, há outros discursos que também legitimam a política curricular e que são produzidos no contexto das diferentes práticas curriculares, uma vez que a ação pode ser determinada de forma diferente, mas não é determinada somente pela política. Nesta situação os atores curriculares, mormente aqueles que estão situados no contexto da escola, são produtores de discursos políticos que legitimam e dão significado ao cotidiano escolar.

As formas de poder explícitas ou implícitas, dos atores que participam na construção do currículo, precisam ser analisadas nos contextos das macro e micropolíticas, correspondentes, respectivamente, às intenções e à prática.

No plano das macropolíticas, pode-se questionar os aspectos da fundamentação e organização dos poderes, não só expressos nos documentos oficiais, mas também nos momentos de produção desses textos.

Nesse sentido, é possível se reconhecer o peso dos grupos socioeconômicos nas práticas de influência e, mais ainda, o papel marcante da administração. O Estado não compreende uma unidade única, porém uma estrutura complexa que existe em virtude de processos que legitimam diferenças de opinião, convertendo a administração, depois de elaborar o corpus legislativo, no seu veículo de regulação da política curricular. (TOALDO, 2020).

Por outro lado, no plano das micropolíticas, cabe abordar a posição das escolas, dos professores e dos alunos no processo de configuração prática do currículo, lugares que nem sempre são controlados totalmente pela administração.

Uma teoria da política da educação, para Pacheco (2003), não pode ser limitada à perspectiva do controle do Estado, visto que, as políticas desenvolvidas costumam ser imperfeitas e simples, ao passo que a prática educativa é sofisticada, contingente, complexa e instável, o que equivale a dizer que nesse plano existem estruturas de poder, redes informais de decisão e práticas discursivas que intervêm de modo ativo na decisão curricular. 
Com efeito, as políticas curriculares são decididas e elaboradas em espaços e vertentes que abrangem lutas e alianças, e que de modo algum se restringem ao conceito racional e operativo da linearidade política. A política curricular não se traduz, desta forma, em uma decisão central substanciada a partir de parâmetros e critérios de âmbito nacional e de modos concretos de regulação da construção cotidiana do currículo. (GELOCHA et al., 2022).

Pelo contrário, a política curricular é aplicada em uma perspectiva interpretativa e menos determinista ou em um conjunto complexo de relações entre a instituição educacional, a experiência individual e a vida pública, ou, ainda, em um espaço de reconstrução de valores, experiências e interesses, visto que a política não se pode esgotar no momento normativo como se o político fosse o único ator a atuar exclusivamente na construção do currículo (PACHECO, 2003).

\section{CURRÍCULO COMO COSTRUÇÃO CULTURAL}

A pluralidade de culturas, etnias, religiões, juntamente com outras dimensões identitárias, tem sido cada vez mais reconhecidas nos diversos campos da vida contemporânea. A complexidade das relações, das tensões e dos conflitos decorrentes de impactos dessas identidades plurais e de suas lutas por afirmação e representação em políticas e práticas sociais extrapola o âmbito da mera reflexão acadêmica. (MOTA; AMARAL, 2017).

Conforme Canen e Moreira (2001), levar em consideração a pluralidade cultural dentro do âmbito educacional e da formação docente implica, deste modo, pensar formas de valorizar e incorporar as identidades plurais em políticas e práticas curriculares.

Implica, também, refletir acerca de mecanismos discriminatórios ou silenciadores da pluralidade cultural que tanto negam voz a diferentes identidades culturais, silenciando manifestações e conflitos culturais, como buscam homogeneizá-las em conformidade com uma perspectiva monocultural. 


\section{AVALIAÇÃO DA MATRIZ CURRICULAR}

Qualquer que seja a discussão em torno de um currículo, não se pode negligenciar que aquilo que se propõe e que se desenvolve nas salas de aula desencadeia um processo de avaliação. Isto significa que a avaliação é parte integrante do currículo, na medida em que a ele se incorpora como uma das etapas do processo pedagógico.

A avaliação é uma a preocupação que ronda o cotidiano das salas de aula, ou seja, a presença da avaliação no cotidiano é permanente. Essa onipresença joga um importante papel no fazer dos alunos, na medida em que os ensina, cotidianamente, comportamentos e atitudes necessários, tanto diante de situações ligadas aos conteúdos quanto diante dos outros momentos da vida escolar, afirma Oliveira e Pacheco (2003).

Atualmente, vem-se observando, no Brasil, a implantação de processos de avaliação generalizados para todos os níveis de escolarização, bem como o uso desses processos como mais uma forma de controle do trabalho pedagógico, o que tem conduzido professores, escolas e alunos a se preocuparem, buscando adaptação às exigências dos exames nacionais para evitar o fracasso e as inúmeras conseqüências dele sobre todos. (AMARAL et al., 2020).

A atual legislação do ensino e as formas clássicas de avaliação da aprendizagem colocam, hoje, para as escolas e para o corpo docente, o desafio de superar pelo desenvolvimento de maneiras alternativas de tratamento dos conteúdos do ensino e de formas de avaliá-los. A restrição do trabalho pedagógico, àquilo que será avaliado pelas provas e testes e, mesmo pelos sistemas de avaliação unificados, hoje, em implementação pelas instâncias governamentais. (AMARAL et al., 2020).

Conforme Oliveira e Pacheco (2003), a incorporação de outros conteúdos, de trabalhos mais abrangentes para além dos conteúdos mínimos e, sobretudo, o desenvolvimento de processo de avaliação da aprendizagem não restrita aos "mínimos", pode evitar que os conteúdos clássicos tornem-se não um mínimo, mas os únicos a serem trabalhados.

A esse respeito, para que os conteúdos mínimos não se tornem somente o que deve ser valorizado nas práticas avaliativas ao serem os únicos momentos de avaliação, um diálogo entre os currículos oficiais, os planejamentos de educadores e a realidade das aulas que a eles se referem faz-se necessário, defende Oliveira e Pacheco (2003). 
As aulas reais, aquelas que estão acontecendo e inevitáveis diálogos com o cotidiano, fornecem materiais sobre o qual os educadores podem e devem debruçar-se no desenvolvimento e na promoção de alterações na proposta curricular e nos mecanismos de avaliação da aprendizagem. Assim, a reflexão em torno das questões curriculares e as tentativas de mudança dos mecanismos de avaliação devem necessariamente caminhar juntos.

\section{CONSIDERAÇÕES FINAIS}

O currículo não pode simplesmente ser entendido como a declaração de áreas e temas, seja ela realizada pela administração ou pelos educadores, mas deve compreender a soma de todo tipo de ações e aprendizagens, bem como de ausências que os educandos obtêm como consequência de estarem sendo escolarizados.

O currículo educacional é uma construção política, sendo que a escola constitui o veículo dessa atividade política, ou seja, uma forma específica de organizar o poder e as influências que se encontraram nas suas práticas cotidianas. No entanto, o currículo não se reduz a uma atividade política, legitimada por uma função burocrática direcionada para a eficiência e melhoria constante.

A política curricular compreende a racionalização do processo de desenvolvimento do currículo com a regulação do conhecimento que constitui a face visível da realidade escolar, juntamente com a função desempenhada por cada ator educativo, dentro de uma certa estrutura de decisões que diz respeito à construção da formação do educando.

Atualmente, outorga-se ênfase à ideia de construção de um currículo que propicie a integração multicultural. No entanto, essa integração somente será possível se a visão multicultural incorporar o currículo comum para todos, para que a integração de culturas seja efetivada dentro de um sistema de escolarização única, caracterizado pelo favorecimento da igualdade de ensejos.

\section{REFERÊNCIAS}

AMARAL, M. F. B.; ALAVARE, O. M.; SILVA, F. A. O desafio da construção de um modelo alternativo de avaliação externa em larga escala da aprendizagem: um desafio, simultaneamente, conceitual, técnico e político como ponto de apoio para o sucesso de 
todos os alunos. Olhar de Professor, v. 23, p. 1-18, 2020. Disponível em: https://www.redalyc.org/jatsRepo/684/68464195007/68464195007.pdf. Disponível em: 20 dez. 2021.

BIANCHI, J. J. P. A Educação e o Tempo: três ensaios sobre a história do currículo escolar. Piracicaba: Unimep, 2001.

CANEM, A.; MOREIRA, A. F. B.. Reflexões sobre o multiculturalismo na escola e na formação docente. In: MOREIRA, A. F. B. (org). Ênfases e Omissões no Currículo. Campinas: Papirus, 2001.

CORAZZA, S. O Que Quer um Currículo? Pesquisas pós-críticas em educação. Petrópolis: Vozes, 2001.

DIAS, A. F.; MENEZES, C. A. A. Que inovação pedagógica a pedagogia queer propõe ao currículo escolar? Revista Tempos e Espaços em Educação, v. 10, n. 23, p. 37-48, 2017. Disponível em: https://seer.ufs.br/index.php/revtee/article/view/7443. Disponível em: 10 dez. 2021.

DUARTE, N. O currículo em tempos de obscurantismo beligerante. Revista Espaço Currículo, p. 139-145, 2018. Disponível em:

https://www.academia.edu/38741177/O_Curr\%C3\%ADculo_em_Tempos_de_Obscura ntismo_Beligerante?auto=citations\&from=cover_page. Disponível em: 15 dez. 2021.

GELOCHA, E. A. N.; ANTUNES, H. S.; LEÃO, D. O. Gestão escolar e (re)construção coletia de projeto políticos-pedagágicos nas escolas do campo: diálogos problematizadores e auto[trans]formativos. Conjecturas, v. 22, n. 1, 2022. Disponível em: https://conjecturas.org/index.php/edicoes/article/view/536. Disponível em: $15 \mathrm{dez}$. 2021.

MENEGOLLA, M.; SANT'ANA, I. M. Por que planejar? Como planejar. 6. ed. Rio de Janeiro: Vozes, 1998.

MONTEIRO, M.; AZAMBUJA, P. Análise cultural de produtos audiovisuais: relato de construção de protocolo teórico-metodológico. Comunicação \& Inovação, v. 19, n. 41, p. 49-66, 2018. Disponível em:

https://seer.uscs.edu.br/index.php/revista_comunicacao_inovacao/article/view/5482/255 2. Disponível em: 20 dez. 2021.

MORAN, J. M. Por onde começar a transformar nossas escolas?. In: MORAN, J. M. (org.). A educação que desejamos: novos desafiose como chegar lá. cap. 6. $6^{a}$ reimp. Campinas: Papirus, 2017. p. 145-165.

MOTA, A. E. S.; AMARAL, A. S. Cenários contradições e pelejas do Serviço Social brasileiro. São Paulo: Cortez Editora, 2017. 
MUYLAERT, N. Avaliação, currículo e o construtivismo. Pesquisa e Debate em Educação, v. 10, n. 2, p. 1274-1286, 2020.

OLIVEIRA, I. B.; PACHECO, D. C. Avaliação e currículo no cotidiano escolar. In: ESTEBAN, M. T. (org.) Escola, Currículo e Avaliação. São Paulo: Cortez, 2003.

OLIVEIRA, I. B.; SÜSSEKIND, M. L. Das teorias críticas às críticas das teorias: um estudo indiciário sobre a conformação dos debates no campo curricular no Brasil. Revista Brasileira de Educação, v. 22, n. 71, e227157, 2017. Disponível em: https://www.scielo.br/j/rbedu/a/mBppqxPsNVcPQskdzhNmdJP/?format=pdf\&lang=pt

PACHECO, J. A. Políticas Curriculares: referências para análise. Porto Alegre, Artmed, 2003.

POPKEWITZ, T. S. Estudos curriculares, história do currículo e teoria curricular: a razão da razão. Em aberto, v. 33, n. 107, p. 47-68, 2020. Disponível em:

http://rbep.inep.gov.br/ojs3/index.php/emaberto/article/view/4555/3775. Disponível em: 20 dez. 2021.

SANTOS, A. M. Escola, sociedade e cultura: a relevância da educação patrimonial na matriz curricular escola. In: SILVA, A. J. N. (org.). Educação: atualidade e capacidade de transformação do conhecimento gerado. Ponta Grossa (PR): Atena, 2020. Disponível em: https://sistema.atenaeditora.com.br/index.php/admin/api/artigoPDF/39669.

Disponível em: 20 dez. 2021.

THIESEN, J. S. Políticas curriculares, educação básica brasileira, internacionalização: aproximações e convergências discursivas. Educ. Pesqui., v. 45, e190038, 2019. Disponível em: https://www.scielo.br/j/ep/a/99G6fThFygFYqSHJZFrkvmM/?format=pdf\&lang=pt. Disponível em: 20 dez. 2021.

TOALDO, A. M. Políticas públicas e os novos paradigmas entre o estado e a sociedade civil: o papel do ativismo comunitário na operação da dicotomia públicoprivado. São Paulo: Editora Max Limonad, 2020. 